\title{
Type A aortic dissection in self-selected patients: What seems to fit a few does not fit all
}

\author{
Ourania Preventza, MD, and Joseph S. Coselli, MD
}

\footnotetext{
From the Division of Cardiothoracic Surgery, Baylor College of Medicine, and Division of Cardiovascular Surgery, Texas Heart Institute, Houston, Tex.

Disclosures: Authors have nothing to disclose with regard to commercial support.

Received for publication Feb 8, 2016; accepted for publication Feb 10, 2016; available ahead of print March 11, 2016.

Address for reprints: Ourania Preventza, MD, BCM 390, One Baylor Plaza, Houston, TX 77030 (E-mail: opsmile01@aol.com).

J Thorac Cardiovasc Surg 2016;151:1593-4

$0022-5223 / \$ 36.00$

Copyright (c) 2016 by The American Association for Thoracic Surgery

http://dx.doi.org/10.1016/j.jtcvs.2016.02.021
}

It is more than a simple curiosity that for patients with an emergent life-threatening condition such as acute type A aortic dissection (Figure 1), there is still no consensus regarding the optimal surgical approach. It is important to note that contemporary results from large registries show a mortality of $18 \%$ to $20 \% .^{1,2}$ Despite the simpler mainstay approach of tube graft replacement of the ascending aorta and hemiarch, cardiac surgery programs are currently evaluating the clearly more aggressive approach of total arch replacement (TAR) with or without frozen elephant trunk (FET).

In this issue of the Journal, Ma and colleagues ${ }^{3}$ evaluate the effectiveness of TAR with FET in 104 patients with acute type A aortic dissection with an arch entry tear, which represents $12.5 \%$ of their cases of acute type A dissection over a 12-year period. They evaluate operative mortality, short- and long-term survival, stroke and spinal cord ischemia rates, the need for late distal aortic reintervention, and follow-up computed tomography data.

In general, in surgical intervention for acute type A aortic dissection, where the main objective is the patient's survival, replacement of the entire total arch is necessary when the aortic arch was aneurysmal before dissection or is rapidly expanding, there is symptomatic brachiocephalic occlusion, or the tear is on the transverse arch and cannot be repaired otherwise. Adjunct FET replacement is performed to treat associated malperfusion syndrome, presumably reducing the need for late aortic reintervention and possibly improving long-term survival.

Ma and colleagues should be congratulated for their outstanding short- and long-term results. They report an operative mortality of $8.6 \%$, a stroke rate of $1.9 \%$, and a renal failure rate of $3.8 \%$-impressive outcomes given the much higher operative mortality rate reported in the current literature. $^{1,2}$ The authors report that their 104 patients were self-selected, in that they survived the first 48 hours after an acute type A aortic dissection and had no end-organ failure, shock, or morbid malperfusion.

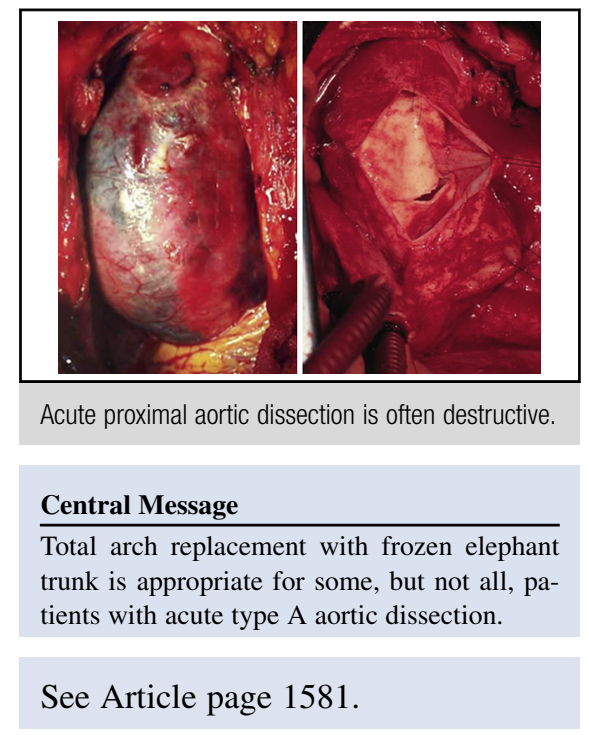

Thus, when reading and interpreting these results, one should not generalize the findings to all patients with acute type A aortic dissection. Nevertheless, the authors' reported operative mortality and stroke rates are arguably remarkably low.

$\mathrm{Ma}$ and colleagues report a spinal cord injury rate of $2.9 \%$, which they justify by pointing out that the postoperative paraplegia might be not attributed to the FET replacement procedure, given that aortic dissection itself may cause paraplegia in up to $5.5 \%$ of cases. ${ }^{2}$ Their strategy for spinal cord protection involved using a shortstent graft, minimizing spinal cord ischemia time with the distal-first strategy, and performing cerebrospinal fluid (CSF) drainage. They mention no adverse events associated with CSF drainage or placement of the CSF catheter, despite the fact that the patients were fully heparinized during cardiopulmonary bypass. They correctly point out that acute type A aortic dissection can result in preoperative spinal cord ischemia. The critical issue is not the total number of patients with paraplegia after acute type A aortic dissection, but rather how many patients are neurologically intact at presentation and develop paraplegia postoperatively. The long-term benefits of a procedure should always be weighed against its short-term risks. In addition, we have previously reported favorable outcomes of late distal aortic operations after acute type I aortic dissection. ${ }^{4}$

One of the main figures in $\mathrm{Ma}$ and colleagues' article depicts the shrinkage of the false lumen and expansion of the true lumen in the stented segment. Although the authors 

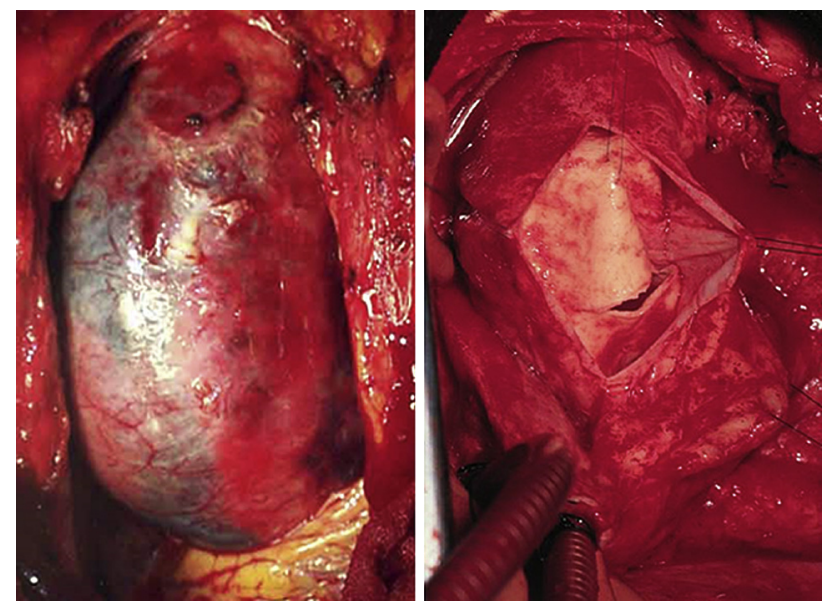

FIGURE 1. Acute proximal aortic dissection.

report having long-term survival data for all patients, their radiographic follow-up rate was only $62.5 \%$. If the false lumen is thrombosed at the time of the operation in some patients, then only patients with a patent false lumen should be included in the denominator when calculating the number of patients who specifically benefit from thrombosis of the false lumen as a direct consequence of the FET replacement. Nevertheless, the authors' findings of false lumen thrombosis, as well as shrinkage in the stented and nonstented segments of the distal aorta, are important. A simpler operation with aggressive hemiarch replacement and antegrade stent delivery instead of full arch replacement can achieve the same distal results.

Treatment of patients with acute type A aortic dissection with arch entry tear is challenging. The results reported by Ma and colleagues support the use of the TAR approach with FET in certain self-selected patients, but these findings should not be generalized to all patients with acute type A aortic dissection.

\section{References}

1. Easo J, Weigang E, Holzl PP, Horst M, Hoffmann I, Blettner M, et al. Influence of operative strategy for the aortic arch in DeBakey type I aortic dissection: analysis of the German Registry for Acute Aortic Dissection Type A. J Thorac Cardiovasc Surg. 2012;144:617-23.

2. Pape LA, Awais M, Woznicki EM, Suzuki T, Trimarchi S, Evangelista A, et al. Presentation, diagnosis, and outcomes of acute aortic dissection: 17-year trends from the International Registry of Acute Aortic Dissection. J Am Coll Cardiol. 2015;66:350-8.

3. Ma WG, Zhang W, Wang LF, Zheng J, Ziganshin B, Charilaou P, et al. Type A aortic dissection with arch entry tear: surgical experience in 104 patients during a 12-year period. J Thorac Cardiovasc Surg. 2016;151:1581-92.

4. Coselli JS, Green SY, Zarda S, Nalty CC, Price MD, Hughes MS, et al. Outcomes of open distal aortic aneurysm repair in patients with chronic DeBakey type I dissection. J Thorac Cardiovasc Surg. 2014;148:2986-94.e2. 